Revista de Estudios Histórico-Jurídicos

[Sección historia de los derechos patrios iberoamericanos]

XLIII (Valparaíso, Chile, 2021)

[pp. 465-490]

\title{
LA JURISDICCIÓN ORDINARIA EN BOGOTÁ A COMIENZOS DE la República. Normatividad, estructura y CONFlictos (Colombia, 1819-Nueva Granada, 1832)
}

[The ordinary jurisdiction in Bogotá at the beginning of the Republic.

Normativity, structure, and conflicts (Colombia, 1819-Nueva Granada, 1832)]

\author{
Carlos Alberto Toro SiLva* \\ Universidad de los Andes, Colombia
}

\begin{abstract}
RESUMEN
A partir del caso de la provincia de Bogotá, este artículo argumenta que en el periodo republicano temprano en Colombia hubo un esfuerzo gubernamental por establecer y formalizar la justicia ordinaria encargada, entre otras funciones, de los juicios criminales. En este contexto el principio de división de poderes resultaba una novedad, y tales cambios comenzaron a tener lugar dentro de una continuidad judicial desarrollada todavía a partir de la cultura jurídica castellana del virreinato de la Nueva Granada. Asimismo aún existían limitaciones materiales para que el Estado en ciernes pudiera sostener un aparato judicial con alcance nacional. Entre las consecuencias de esa situación estuvo la importancia que adquirieron los alcaldes municipales de los cantones como jueces de
\end{abstract}

ABstract

* Doctor en Historia de la Universidad de los Andes, Colombia. El artículo es resultado de la investigación doctoral Politica penal, justicia ordinaria y delincuencia patrimonial. Santa Fe-Bogotá, 1739-1836, financiada por el Departamento administrativo de ciencias, tecnología e innovación Colciencias (actualmente Ministerio de Ciencias) de Colombia. Dirección postal: carrera 3A 46-78 Bogotá, Colombia. Dirección electrónica: ca.toro964@uniandes.edu.co. ORCID: 00000002-2401-1404. 
primera instancia, así como los conflictos de competencia suscitados durante el periodo. Para la investigación se consultaron fuentes constitucionales y legales, informes gubernamentales y documentos de archivo.

Palabras clave

Justicia ordinaria - jueces - Constitución - ley - jurisdicción - competencia - división de poderes. reports and archival documents were consulted for the investigation.

\section{KEY WORDS}

Ordinary Justice - Judges - Constitution - Law - Jurisdiction - Division of Powers.

RECIBIDO el 24 de abril de 2020 y ACEPTADO el 27 de enero de 2021

\section{INTRODUCCIÓN}

Este artículo analiza la estructura de la justicia ordinaria a comienzos de la República, un asunto poco explorado en Colombia. La investigación se centró en el territorio de la antigua jurisdicción de Santa Fe, capital del virreinato, y, desde 1819, con el nombre de Bogotá, de la naciente república. El texto pretende dar cuenta de los cambios que entre 1819 y 1832, año de la Constitución de la República de la Nueva Granada, implicaron una reorganización y resignificación de la justicia ordinaria encargada, entre otros asuntos, de juzgar los delitos, en especial los hurtos, que se habían incrementado después de la Independencia ${ }^{1}$. Estos cambios, a su vez, interactuaban con continuidades de la cultura jurídica vigente caracterizada por el peso del poder jurisdiccional como autoridad pública, como se verá2.

Una preocupación central del vicepresidente Francisco de Paula Santander y del presidente Simón Bolívar era la construcción del poder judicial, así como una justicia criminal efectiva ante la delincuencia creciente. Esto implicaba un gran esfuerzo cultural pues, como señala Armando Martínez, "se trataba de transitar del régimen indiano, en el que la función de la justicia era el corazón de un estado que reunía todas las funciones públicas, a un nuevo régimen republicano en el

${ }^{1}$ Como muestro en mi tesis doctoral Justicia penal contra los hurtos, justicia ordinaria y delincuencia patrimonial. Santa Fe-Bogotá, 1739-1836 (2019). Luego de la Independencia creció la población de la capital, sobre todo debido a la migración de los desmovilizados de la guerra, con lo que aumentó la miseria urbana y la delincuencia. Esta situación fue registrada en la prensa, además de generar una creciente preocupación entre los habitantes de la ciudad y el gobierno, lo que motivó la expedición de la ley contra los hurtos de 3 de mayo de 1826.

${ }^{2}$ Para el caso de México en un periodo más amplio del siglo XIX, Georgina López ha encontrado un elemento de continuidad en las instituciones judiciales y en la cultura jurídica. López GonzÁLEZ, Georgina, Jueces y magistrados del siglo XIX: continuidad jurídico-institucional en México, en Nuevo Mundo Mundos Nuevos (2012) [disponible en http://journals.openedition. org/nuevomundo/62666]. Para el caso argentino, por ejemplo, AgüEro, Alejandro, Formas de continuidad del orden juridico. Algunas reflexiones a partir de la justicia criminal de Córdoba (Argentina), primera mitad del siglo XIX, en Nuevo Mundo Mundos Nuevos (2010) [disponible en http:/ journals. openedition.org/nuevomundo/59352]. 
que las funciones tendrían que separarse e independizarse, y en el que la función de justicia fue rebajada a la condición de miembro inferior" ${ }^{3}$. Incluso en 1832 en la región más central de la naciente República no puede hablarse de un tránsito o transición completos entre uno y otro modelo, sino de una situación enmarcada dentro de esa transición.

Los cambios en el terreno normativo-discursivo habían comenzado en 1811 con el Acta de la Federación de las Provincias Unidas de Nueva Granada, que consagraba la división de poderes y el derecho de las provincias de establecer de juzgados y tribunales. Ese año, además, la misma Federación redactó un Reglamento para el gobierno y organización de la Alta Corte de Justicia de las Provincias Unidas de la Nueva Granada, institución que no llegó a entrar a cumplir funciones judiciales. Otras reformas estuvieron en las constituciones provinciales como las de Cundinamarca de 1811 y 1812, en las que también se consagraba el principio de división de poderes y la conformación del poder judicial de la provincia.

Más adelante, la composición de la justicia ordinaria de primera y segunda instancia comenzó a su vez a sufrir transformaciones en la distribución de las funciones de los jueces. Así, aunque inicialmente los alcaldes ordinarios de Bogotá (nombre que recibió Santa Fe desde 1819) conservaron la c o m p e t e n c i a en primera instancia, a partir de la reforma de 1825 aquella comenzó a distribuirse en los alcaldes municipales de los cantones, lo que implicaba una desconcentración de la justicia de primera instancia que hasta entonces había estado concentrada en los alcaldes ordinarios de la capital.

Para el caso colombiano el primer historiador que se refirió a la formación del poder judicial fue David Bushell en su libro sobre el régimen de Santander, en el que señala que tradicionalmente no se había puesto "prácticamente ninguna atención a la rama judicial y muy poca al trabajo interno de la legislativa, lo que a su juicio se debía a que el "desarrollo político de América Latina se caracteriza por la concentración de poder en manos del ejecutivo"4. A pesar del tiempo transcurrido entre su obra y el presente, la afirmación de Busnhell sigue teniendo cierta validez, pues incluso hoy la historiografía colombiana sobre las primeras décadas republicanas continúa privilegiando el estudio del gobierno (es decir, de la rama Ejecutiva). Por el contrario, en Argentina y México existen investigaciones que han dado cuenta de los alcances y límites de los cambios en la organización de la administración de justicia en el periodo republicano temprano ${ }^{5}$.

De todos modos, para el caso colombiano existen algunos trabajos como el de Francisco Roberto Barbosa que revisa las leyes relacionadas con el "aparato judicial en el proceso de configuración del Estado-Nación en Colombia” entre 1821 y

${ }^{3}$ Martínez Garnica, Armando, La Agenda de Colombia (Bucaramanga, 2008), pp. 114 y 115.

${ }^{4}$ Bushnell, David, El régimen de Santander en la Gran Colombia (Bogotá, 1966 [1954]), pp. 63-68.

${ }^{5}$ Para el caso mexicano un balance reciente: Galante, Miriam, La historiografía reciente de la justicia en México, siglo XIX: perspectivas, temas y aportes, en Revista Complutense de Historia de América, 37 (2011), pp. 93-115. Una introducción a la historiografía argentina, por ejemplo: BARRIERA, Darío, Justicias, jueces y culturas jurídicas en el siglo XIX rioplatense, en Nuevo Mundo Mundos Nuevos (2010) [Disponible en http://journals.openedition.org/nuevomundo/59252]. Asimismo, Barreneche, Owaldo, Crime and the Administration of Justice in Buenos Aires, 1785-1853 (Lincoln, 2006). 
1853. Por su parte, el texto de Germán Colmenares muestra la continuidad de las leyes castellanas en los juicios criminales en medio de la recepción de las ideas penales ilustradas y liberales por parte de algunos operadores judiciales ${ }^{6}$. El tercer gran aporte es el trabajo antes citado de Armando Martínez Garnica, que enmarca la creación y establecimiento de las cortes de justicia dentro de la a g e n d a de los primeros gobiernos republicanos, lo que indica que, al igual que el trabajo de Bushnell, se trata de un estudio enfocado en la dimensión administrativa del Estado ${ }^{7}$. Para el caso de Antioquia está el artículo de Juan Carlos Vélez Rendón ${ }^{8}$.

El presente trabajo comenzará por explorar los cambios constitucionales en relación con la administración de justicia. Luego se examinarán, primero, los cambios territoriales que modificaron la organización territorial alrededor de la capital, al convertir los corregimientos en cantones; segundo, la división de poderes, y, tercero, la noción de juez natural o juez legal. Después se estudiarán los cambios en las nociones de jurisdicción y competencia. La sección que sigue se referirá a la composición y reorganización de la justicia criminal, y, finalmente se examinarán algunos de los conflictos de competencia que podían darse dentro de una incipiente división de poderes. Todo lo anterior servirá para comprender la estructura de la incipiente justicia ordinaria republicana encargada de controlar los delitos en el territorio de la capital y los cantones circundantes cuyo territorio había formado parte de su jurisdicción. La investigación se basó el documentos del Archivo General de la Nación (en adelante AGN), textos legales y constitucionales, y en informes gubernamentales.

\section{CAmbios territoriales (1815-1831)}

En el periodo colonial la jurisdicción de Santa Fe, a pesar de carecer de límites claros, era un territorio definido precisamente por el ejercicio de la jurisdicción en primera instancia, y que abarcaba los corregimientos localizados alrededor de la capital'. Posteriormente, como señala Roberto Velandia, la Constitución de la provincia de Cundinamarca de 1815 estableció la división del territorio en nueve cantones, siguiendo la antigua división de Partidos y Corregimientos ${ }^{10}$, de los cuales cinco pertenecían a la antigua jurisdicción de Santa Fe (Bosa, Ubaque, Zipaquirá, Bogotá y Chocontá). Este documento constitucional tuvo una vigen-

${ }^{6}$ Colmenares, Germán, El manejo ideológico de la ley penal en un periodo de transición, en Historia Crítica, 4 (1990), pp. 5-45.

${ }^{7}$ Martínez Garnica, Armando, cit. (n. 3).

${ }^{8}$ Vélez RENDÓn, Juan Carlos, El establecimiento local de la administración de justicia en Antioquia, 1821-1853. El difícil cumplimiento de una promesa republicana, en Anuario Colombiano de Historia Social y de la Cultura, 40/1 (2013), pp. 113-143.

${ }^{9}$ Sobre las divisiones territoriales a finales del virreinato: Herrera Ángel, Marta, Las divisiones politico-administrativas del Virreinato de la Nueva Granada a finales del periodo colonial, en Historia Crítica, 22 (2001), pp. 76-98.

${ }^{10}$ Velandia, Roberto, Enciclopedia bistórica de Cundinamarca (Bogotá, 1979), I, p. 163. El autor se refiere en realidad al Plan de reforma de 1815. Plan de reforma o revisión de la Constitución de la provincia de Cundinamarca del año 1812. Sancionado por el Serenísimo Colegio Revisor y Electoral de la misma en sesiones tenidas desde el mes de junio hasta el trece de junio de 1815 (Santa Fe, 1815). 
cia limitada, aunque el cantón como unidad territorial asimilable a los anteriores corregimientos se mantuvo en la Constitución colombiana de 1821.

\section{Mapa 1. Provincia de Cundinamarca (de Bogotá desde 1821) en $1815^{11}$}

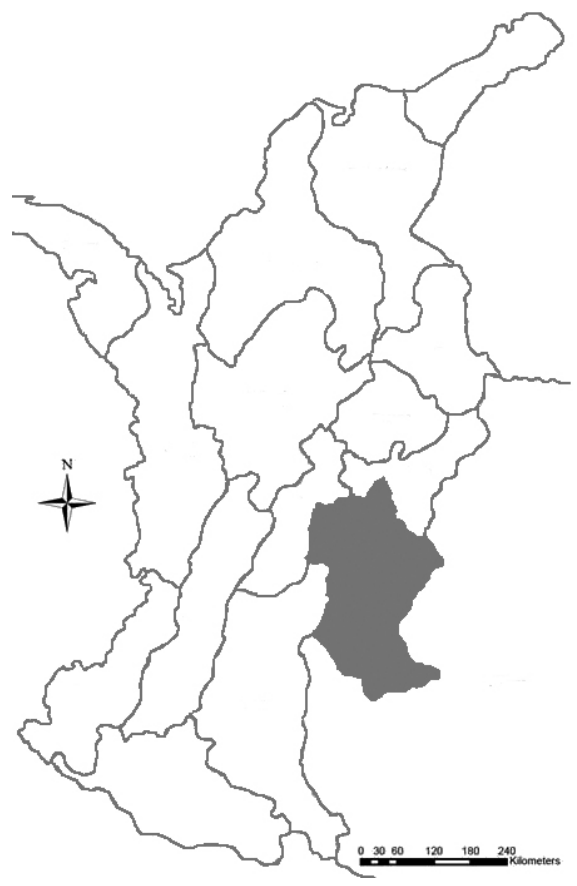

La Constitución de Cúcuta mantuvo la división territorial en provincias y cantones, añadiendo la de departamentos, dentro de los que estaban las provincias. De acuerdo con el artículo 7 de la ley 25 de 1824, la provincia de Bogotá, una de las cuatro del departamento de Cundinamarca, estaría dividida en 11 cantones: 1. Bogotá; 2. Funza; 3. La Mesa; 4. Tocaima; 5, Fusagasugá; 6. Cáqueza; 7. San Martín; 8, Zipaquirá; 9. Ubaté; 10. Chocontá, y 11. Guaduas. Más adelante, en 1831, se suprimirían los departamentos por la ley de 21 de noviembre de ese año ${ }^{12}$, y la Constitución de 1832 estableció que el territorio se dividiría "en provincias, las provincias en cantones, los cantones en distritos parroquiales" (art. 150).

Así, la nueva división territorial republicana de la provincia en cantones tomaba como base los antiguos corregimientos, puesto que la antigua jurisdicción

${ }^{11}$ Este mapa está basado en el realizado por Pinto Bernal, José Joaquín y Torres Moreno, James Vladimir, Guerra y Fisco en la Nueva Granada, 1811-1824, en Revista de Economia Institucional, 18/35 (2016), p. 178. Vale la pena aclarar que la provincia de Cundinamarca de 1815 (antes de Santa Fe) pasó a llamarse provincia de Bogotá en 1821, como parte del nuevo departamento de Cundinamarca de la República de Colombia.

${ }^{12}$ Previamente, la reforma de 1815 a la Constitución de Cundinamarca de 1812 había dividido el territorio de la provincia de Cundinamarca en nueve cantones, formados, siguiendo la antigua división y corregimientos. VeLANDia, Roberto, cit. (n. 10), pp. 163 y 164. 
de Santa Fe incluía los de Bogotá, Bosa, Zipaquirá, Chocontá, Ubaté y Cáqueza, que se convertirían en sendos cantones. De todos modos, el territorio de la nueva provincia era más amplio, al incluir cantones como Tocaima y San Martín, cuyos territorios habían formado parte de otras jurisdicciones. Esta división tendría consecuencias en la distribución territorial de las competencias judiciales, puesto que el gobierno de Santander estableció en 1825 los jueces letrados y los jueces municipales para los cantones, quienes se encargarían de conocer las causas criminales en primera instancia. Así, la justicia ordinaria de la provincia de Bogotá, que antes estaba concentrada en los alcaldes ordinarios del cabildo y la Real Audiencia (y los corregidores, a pesar de su decadencia como jueces ordinarios a finales del virreinato), a quienes los jueces inferiores debían remitir los sumarios, comenzó a desconcentrarse en los alcaldes municipales. Aunque la ley de 11 mayo de 1825 creó los jueces letrados de primera instancia, en la práctica el conocimiento de las causas criminales terminó siendo asumido por los alcaldes municipales, puesto que el gobierno carecía de recursos suficientes para sostener a los jueces letrados tal como los proyectó, es decir, para todos los cantones.

A pesar de los cambios territoriales, en el interior de la capital no parecen haber ocurrido transformaciones importantes en la organización del territorio. Por ejemplo, los barrios en los que había sido dividida la ciudad para facilitar las actuaciones de los alcaldes de barrio se mantuvieron; el cambio fue nominal: aquellos solamente comenzaron a llamarse alcaldes parroquiales, al igual que los de las parroquias en los otros cantones de la provincia.

\section{División DE PODERES Y AUTORIDADES DEL PODER JUDICIAL EN LAS CONSTITUCIONES (1811-1832)}

El gobierno republicano temprano buscaba crear y establecer un poder judicial para el nuevo territorio soberano. Esto implicaba la necesidad de centralizar y formalizar legalmente el aparato judicial existente, comenzando por las definiciones constitucionales, y luego con disposiciones legales ${ }^{13}$.

Las Constituciones de Cundinamarca, de 1811, colombiana de 1821 y de la República de la Nueva Granada de 1832 incluían el principio de división de poderes, siguiendo el modelo francés y estadounidense ${ }^{14}$. El orden de los poderes era también el mismo, con el legislativo y ejecutivo en primer y segundo lugar, respectivamente, y el judicial al final ${ }^{15}$. En esta secuencia, como señala Bartolomé Clavero refiriéndose al constitucionalismo revolucionario francés, no hay una

${ }^{13}$ Aquí entiendo por formalización la tendencia hacia la solución de los conflictos sociales dentro de los términos de las leyes y en el ámbito la administración de justicia ordinaria.

${ }^{14}$ En el uso de esta denominación se diferenciaban de la Constitución de Cádiz de 1812, que incluía ese principio bajo la denominación de potestades. BALAguer CaLLejón, María Luisa, La división de poderes en la Constitución de Cádiz de 1812, en Revista de Derecho Político, 83 (2012), pp. 18-41. Díaz Bravo, Enrique, La separación de poderes en la primera constitución española, en Nómadas. Revista Crítica de Ciencias Sociales y Jurídicas, 33 (2012), pp. 275-293.

${ }^{15}$ Clavero, Bartolomé, El orden de los poderes. Historias constituyentes de la trinidad constitucional (Madrid, Trotta, 2007). 
lógica más allá que la determinada por la misma constitución ${ }^{16}$. En el caso colombiano, como se verá más adelante, esta lógica ponía al poder judicial en una posición subordinada al Ejecutivo, dominado por políticos y militares participantes en la revolución de Independencia.

Las tres Constituciones incluían sendos títulos referidos al poder judicial ${ }^{17}$. En la Constitución de 1811 ese poder estaba desarrollado en tres artículos, uno de los cuales establecía sus limitaciones con respecto a los otros poderes ${ }^{18}$. Una particularidad de las constituciones de 1811 y 1821 es que incluían definiciones de índole material sobre el poder judicial. La Constitución de Cundinamarca de 1811 definía de esta forma: "Título VII. Del Poder Judicial. Artículo 1.- El Poder Judicial consiste en la autoridad de examinar las diferencias que se suscitan entre los ciudadanos, fijar sus derechos, juzgar sus demandas y querellas, y aplicar las penas establecidas por las leyes a los infractores de ellas. El uso ordinario de estos juicios es lo que propiamente se dice Poder Judicial [...]". Este artículo es ilustrativo no solo del predominio de criterios materiales sobre los formales a la hora de distinguir un poder público de los otros, sino además de lo artificiosa que resultaba aún la idea de división de poderes en este periodo. Esto se ve, por ejemplo, en la advertencia que hacía de que los magistrados no tuvieran parte en la representación nacional.

El ejercicio del poder judicial correspondería a los "Tribunales de la provincia" (Título I art. 8). Estos tribunales serían, en primer lugar y "preferente a todos los demás" el Senado; después siguen los de apelación, y, "últimamente", los "Jueces de Primera Instancia con sus municipalidades", y los pedáneos con las pequeñas municipalidades que debía "haber en todo poblado por pequeño que sea". Llama la atención que una entidad de índole política de acuerdo con sus orígenes romanos, como el Senado, apareciera como tribunal de tercera instancia, pero esto, de nuevo, se comprende al considerar que en el marco de la cultura jurídica castellana vigente en Hispanoamérica el poder político y la jurisdicción eran equivalentes, y la Constitución de 1811 se trataba de un ensayo muy temprano de establecer la división de poderes. El Senado y los tribunales de apelación debían reemplazar a la Real Audiencia como instancias superiores de justicia, lo que no sucedió, puesto que dicho tribunal siguió existiendo en la capital hasta 1819, y en Cartagena hasta 1821. De hecho, con la Constitución de 1812 el Senado pasó a ser uno de los dos componentes del poder legislativo y sí llegó a crearse ${ }^{19}$. La composición del poder judicial fue modificada en la Constitución de 1812, en cuyo título VI se indicaba que los tribunales serían la Sala de Apelaciones, la de Reposición, la de Protección, el Consejo de Guerra, y la Comisión de residencia. La justicia inferior estaría en los juzgados de primera instancia.

La estructura de la justicia inferior de la provincia tampoco sufrió alteraciones

${ }^{16}$ Ibíd., p. 120.

${ }^{17}$ VII, en el caso de la de 1811, VI en la de 1821, y VII en la de 1832.

${ }^{18}$ Artículo 2: "Solamente son del resorte del Poder Judicial las materias contenciosas, bajo el aspecto de tales; y por ningún caso podrá entrometerse en lo relativo a los Poderes Ejecutivo y Legislativo, aunque sea de un asunto contencioso".

${ }^{19}$ Sosa Abella, Guillermo, Representación e Independencia 1810-1816 (Bogotá, 2006), pp. 79 y 203 . 
en el periodo comprendido entre 1810 y 1825, puesto que los alcaldes ordinarios no fueron reemplazados por los jueces de primera instancia de las constituciones de 1811 y 1812, y los pedáneos continuaron bajo esa misma denominación. El cambio de estos jueces por sus versiones republicanas, los alcaldes municipales y parroquiales, respectivamente, solo tendría lugar en 1825.

Por su parte, la Constitución de 1821, además del título VI sobre el Poder Judicial, incluía en su alocución final dirigida a los "colombianos" una definición de dicho poder caracterizada por la retórica política republicana: "El Poder Judicial donde los asaltos de la intriga pierden toda su fuerza y el rico todo su ascendiente; a donde nadie puede llegar con rostro sereno si no va revestido con los simples adornos de la justicia, está destinado a dirimir imparcialmente vuestras contiendas, reprimir al malvado y favorecer la inocencia; en tan respetuoso lugar rinden todos homenaje a la ley; y alli veréis las pasiones desarmadas, cortadas las tramas del artificio y descubierta la verdad". Aquí se ve que para los constituyentes de 1821 las disposiciones constitucionales sobre el poder judicial no podían h a bla r por sí mismas, sino que necesitaban la introducción de la voz de sus autores para aclarar su sentido material, en este caso sobre la justicia.

Por el contrario, la Constitución de 1832 no incluía una definición al estilo de la anterior. Solamente establecía en su artículo 130 que la justicia se administraría por "por una corte suprema de justicia, y los demás tribunales y juzgados que la ley establezca". De este modo, si las anteriores constituciones definían materialmente el poder judicial, es decir de acuerdo con el contenido y sentido de su actividad, la de 1832 solo separaba funcionalmente las ramas del poder público y establecía en términos amplios las autoridades que se encargarían de desarrollar tales actividades, como la administración de justicia.

\section{El JUEZ LEGAL EN LAS CONSTITUCIONES DE 1821 y 1832}

El derecho al juez legal aparecía en los textos constitucionales de 1821 y 1832 de maneras distintas, aunque la garantía fuera la misma. En el caso de la Constitución de 1821, establecía en su artículo 166 "que nadie podía ser juzgado por comisiones especiales sino por tribunales a quienes corresponda el caso por las leyes". Así, en la ley estaría el fundamento para determinar quién debía juzgar; es decir, de la jurisdicción. En el caso de la de 1832, la disposición al respecto (art. 182) determinaba que "ningún granadino podrá ser distraido de sus jueces naturales, ni juzgado por comisiones especiales, ni por tribunales extraordinarios".

Estas disposiciones constitucionales se enmarcaban en el discurso normativo recogido por los gobernantes republicanos del lenguaje revolucionario norteamericano y, en este caso, francés ${ }^{20}$. No eran resultado de que efectivamente vinieran operandocomisiones especiales o tribunales extraordi$\mathrm{n}$ a ri os para juzgar delitos comunes, que en todos los casos eran conocidos por los jueces ordinarios, que durante el virreinato era en la jurisdicción de Santa Fe los alcaldes ordinarios, la Real Audiencia y los corregidores. Las comisiones

\footnotetext{
${ }^{20}$ Por ejemplo, el artículo 63 de la carta constitucional francesa de 1814 establecía que no podrían crearse comisiones y tribunales extraordinarios.
} 
estaban limitadas a la etapa del sumario, así que los comisionados no podían actuar como jueces extraordinarios puesto que no podían sentenciar. Además, el Tribunal de la Inquisición conocía solo de un tipo específico de delitos, pero, precisamente debido a su condición de extraordinario, fue abolido en 1821 por el Congreso Constituyente de Colombia ${ }^{21}$.

Resulta de interés observar la interpretación de la idea de juez legal en las controversias judiciales del periodo republicano temprano. En 1827, por ejemplo, uno de los magistrados de la Corte superior departamental de Cundinamarca se valía del mencionado artículo 166 para su salvamento de voto en una consulta sobre una sentencia de último suplicio por el robo de las alhajas de la parroquia de Chía. En primera instancia, las confesiones de los reos habían sido tomadas sin presencia del alcalde municipal ni del escribano, por lo que el defensor propuso la ex ce pción de n ulidad del proceso. El magistrado se apoyaba en la legislación castellana para argumentar la obligatoriedad de la presencia del alcalde en la confesión y para resaltar que la confesión ante juez incompetente era ipso jure nula, “y de ella de ningún modo puede seguirse la condenación del reo, especialmente si la incompetencia del rey es por falta de jurisdicción, como lo fundan los prácticos entre ellos Antonio Gómez [...] y Hevia Bolaños [...]"22. Más adelante señalaba que, en conformidad con el artículo 166 de la Constitución, nadie podía ser juzgado por comisiones especiales, sino por los tribunales a quienes correspondía el caso por las leyes, de lo que se seguía, a su juicio, que ni el alcalde municipal pudo cometer al asesor las confesiones, y que habiéndolas tomado por sí solo, además de la nulidad del proceso se había cometido "la falsedad de asegurarse y dar fe que se tomaron por el alcalde y escribano",23.

El mismo artículo 166 era invocado por la Corte para criticar la falta de arreglo de los juzgados eclesiásticos en varios puntos a las leyes de la República sobre administración de justicia. La Corte señalaba que los juzgados eclesiásticos pronunciaban sentencias sin dictamen de asesor letrado, a pesar de que el artículo 163 de la ley orgánica del poder judicial disponía que ningún juez “civil, eclesiástico o militar" podía pronunciar sentencia sin exigir tales dictámenes ${ }^{24}$. Además afirmaba que, a pesar de la prohibición del artículo 166, había vicarios generales capitulares en la República que comisionaban especialmente a otro eclesiástico, "para la resolución definitiva de los procesos; y no solo para esta o aquella causa, sino también para la universalidad de ellas. Esto manifiesta la necesidad de que la ley designe cuáles son los medios de hacer efectiva la responsabilidad de los jueces eclesiásticos" ${ }^{25}$. Estos dos casos muestran que la disposición constitucional sobre el juez legal fue reconocida por la Corte, interesada por la incorporación de la actividad judicial en general a los términos de la legalidad.

La Constitución de 1832 consagró el derecho al juez legal en el artículo 182, que rezaba "Ningún granadino podrá ser distraído de sus jueces naturales, ni juzgado por

\footnotetext{
${ }^{21}$ Martínez Garnica, Armando, cit. (n. 3), pp. 103 y 104.

${ }^{22}$ AGN, Sección República, Juzgados y Tribunales, tomo 20, f. 378 r. y v.

${ }^{23}$ Ibíd., f. 378v. y 379r.

${ }^{24}$ Ibíd., f. 432 r.

${ }^{25}$ Ibíd., ff. 432r.-433v.
} 
comisiones especiales, ni por tribunales extraordinarios". Esta disposición tiene que ver con un problema que atraviesa toda la República temprana: la tensión entre el lenguaje con el que se pretendía organizar la sociedad en la Constitución y las leyes, y los problemas específicos con los que los gobernantes se enfrentaban.

Aquí surge la pregunta ¿a qué jueces “naturales” se refiere esta disposición? La norma copia los artículos 62 y 63 de la carta constitucional francesa de 1814; sin embargo, como ha mostrado Ulrike Müßig, la garantía del juez natural "evoca el derecho natural estamental de la justicia, continuado por la mediación del poder del Estado a través de los poderes nobiliarios intermedios" ${ }^{26}$. Su consagración en dicha carta implicaba la continuidad entre reivindicaciones estamentales (opuestas a los jueces extraordinarios nombrados por el Rey incluso desde la Edad Media pues privaban a los juzgados ordinarios de la jurisdicción que les correspondía por naturaleza) y constitucionales. Esto significa, como muestra Müßig, que no se trataba de una "nueva creación de los derechos individuales de la ilustración" ni era resultado de la introducción de una separación de poderes basada en la soberanía popular ${ }^{27}$. En síntesis, la noción constitucional de juez natural resultaba de una situación francesa que se remontaba a periodos muy anteriores al revolucionario, y que poco tenía que ver con la del imperio español, en donde el crecimiento la justicia real no se manifestaba a través del establecimiento de comisiones extraordinarias para juzgar a los súbditos ${ }^{28}$, y particularmente de sus colonias, en donde ese tipo de disposiciones no podían tener mucha eficacia.

Particularmente, en el virreinato de la Nueva Granada la administración de justicia criminal estaba en manos de los jueces ordinarios. Las comisiones utilizadas por los alcaldes ordinarios de Santa Fe, y sobre todo por la Real Audiencia siempre estaban limitadas al sumario. No implicaban una transferencia de la jurisdicción ordinaria al inferior. No existían jueces comisionados o extraordinarios como los que habían originado los conflictos franceses entre los poderes estamentales y la Corona que buscaba imponer su justicia a través de la figura extraordinaria de los comisionados. Los jueces "naturales" de la población, entonces, eran aquellos que la ejercían en nombre del rey y que gozaban de legitimidad entre la población precisamente por ese motivo. En la sociedad colonial neogranadina, en la que no había poderes señoriales (y por tanto, justicias de esa naturaleza), no había jurisdicciones ordinarias al margen de las que residían en las ciudades y sus términos.

De acuerdo con lo anterior, la referencia constitucional de 1832 al juez natural debe entenderse ante todo como una declaración de principios, o posiblemente una autolimitación estatal para el futuro a partir modelo constitucional francés. Se trata de una disposición que no tenía un sustento en la realidad neogranadina, a diferencia de la situación francesa ya referida.

\footnotetext{
${ }^{26}$ Müssig, UlRiKe, El juez, legal (Madrid, 2014), p. 119.

${ }^{27}$ Ibíd., pp. 120, 121 y 142, 143.

${ }^{28}$ Además de que los juristas españoles tendían a calificar de odiosa la justicia extraordinaria frente a la ordinaria.
} 


\section{Vigilancia del Poder Ejecutivo sobre el Judicial para el} CUMPLIMIENTO DE SUS FUNCIONES A COMIENZOS DE LA REPÚBLICA

El interés del gobierno por subordinar el Poder Judicial al Ejecutivo se observa tanto en sus discursos como en las disposiciones normativas sobre la organización de la justicia. Esta posición no era nueva: los constituyentes de la provincia de Cundinamarca habían consagrado la prohibición al Ejecutivo de entrometerse en el ejercicio y las funciones del Poder Judicial, reconociendo, de todos modos, su deber de "asegurar la observancia de la Constitución en los Tribunales" (Título V art. 33 de la Constitución de 1811). De hecho, incluso bajo la dominación monárquica -es decir antes del constitucionalismo republicano y la división de poderes-, la Corona había determinado que los virreyes neogranadinos debían velar por una eficaz administración de justicia ${ }^{29}$. Después de la Independencia el control gubernamental sobre la administración de justicia se convirtió, en términos de Armando Martínez Garnica, en una "agenda permanente" del gobierno ${ }^{30}$. En la Constitución de 1821 el Ejecutivo se arrogó la responsabilidad de cuidar de que el poder judicial administrara justicia "pronta y cumplidamente".

Asimismo, la ley orgánica del Poder Judicial de 11 de mayo 1825 atribuyó al Poder Ejecutivo la facultad exclusiva de suspender a sus agentes, disposición que llegó a causar incomodidad entre algunos de los magistrados. En un informe redactado por solicitud del gobierno, por ejemplo, los ministros de la Alta Corte de Justicia señalaban que el Ejecutivo no dejaba arbitrio a los tribunales y juzgados para levantar o revocar esa suspensión en caso de hallarla "injusta o ilegal”, sino que por fuerza debía adelantar el procedimiento. A su juicio, era una “nueva dependencia del poder ejecutivo" bajo la cual se ponía al poder judicial, "y una violencia que se hace a la conciencia de los jueces que tienen que estar forzosamente por lo que haya declarado el poder Ejecutivo" 31 . Debe recordarse que la autoridad jurisdiccional implicaba tradicionalmente en la práctica un amplio margen de discrecionalidad para los jueces, lo que explica la resistencia de los magistrados de la Corte ante la prerrogativa que se atribuía el Ejecutivo.

El propio Bolívar señalaba posteriormente, en su decreto de 24 de noviembre de 1826, que el Ejecutivo velaría por que los jueces municipales de primera instancia administraran "pronta y cumplidamente justicia" con el objeto de castigar a los "omisos o negligentes". En otras palabras, para el gobierno colombiano el Poder Judicial estaba subordinado a él, lo que de hecho quedó establecido constitucional y legalmente como se ha visto. Asimismo, el Secretario de Estado José Manuel Restrepo parecía especialmente interesado en la subordinación de la actividad de los jueces a la de los legisladores, y particularmente de los gobernantes. En

\footnotetext{
${ }^{29}$ Ots Capdequí, José María, Nuevos aspectos del siglo XVIII español en América (Bogotá, 1946), p. 43.

${ }^{30}$ Martínez Garnica, Armando, cit. (n. 3), 111.

${ }^{31}$ Observaciones que la alta Corte de Justicia, con motivo de la excitación hecha por el Poder Ejecutivo en nota de 3 de nov.e del año anterior hace acerca de algunas imperfecciones o vacios, que en su concepto son más notables en el presente estado de la legislación, relativo a la administración judicial, En AGN, Sección República, Juzgados y Tribunales, Legajo 20, f. 426r.
} 
1826, en su informe al Congreso solicitaba, como cabeza del Ejecutivo, la "activa cooperación de los jueces y tribunales para cumplir las leyes" que hubiera "acordado el cuerpo legislativo" para para hacer desaparecer los delitos que se habían hecho más frecuentes luego de la guerra ${ }^{32}$. Más adelante, en su informe del año siguiente, criticaba la "equivocada independencia en que se creen los jueces de la supervigilancia del poder ejecutivo o de sus agentes para hacerles cumplir" 33 . En el mismo documento hacía explícita la posición de superioridad del Ejecutivo sobre el poder judicial, al quejarse de que el primero no había podido tener sobre el poder judicial el influjo que parecía necesario para que todos sus miembros cumplieran con sus deberes. A juicio de Restrepo, "Acaso la independencia del poder judicial se ha llevado al extremo entre nosotros, negando al ejecutivo funciones que tienen otros gobiernos bien constituidos, y que naturalmente corresponden al jefe de la administración. Sin duda los jueces también ejecutan las leyes aplicándolas a los casos particulares, y, por consiguiente, debieran estar bajo la supervigilancia del gobierno. El artículo 124 de la Constitución parece que dio al ejecutivo esta influencia cuando dispuso 'Cuidará de que la justicia se administre [sic] pronta y cumplidamente" 34 . La afirmación de Restrepo muestra el interés gubernamental por limitar el arbitrio de los jueces través de la subordinación del Poder Judicial tanto a las propias leyes como al gobierno, es decir, el Poder Ejecutivo.

\section{SigNIFICADO DE LA JURISDICCIÓN Y LA COMPETENCIA A COMIENZOS DE LA REPÚBLICA}

En el artículo 126 de la Constitución de 1821 apareció por primera vez la idea de jue z competen te, que a simple vista no parece revestir mayor importancia, pero que, teniendo en cuenta que la noción de competencia se refería a un conflicto de jurisdicción, implica un cambio importante: la competencia como distribución funcional y territorial de la jurisdicción.

El tránsito de la jurisdicción monárquica a la soberanía republicana implicó transformaciones en el significado de la primera de esas nociones ${ }^{35}$. De todos

\footnotetext{
${ }^{32}$ Restrepo, José Manuel, Mensaje del vicepresidente de Colombia encargado del gobierno al Congreso de 1826, en Gómez Rodríguez, Luis Horacio (comp.), Administraciones de Santander (Bogotá, 1990), II, p. 24.

${ }^{33}$ Restrepo, José Manuel, Exposición que el secretario de Estado del despacho del interior del gobierno de la República de Colombia hace al Congreso de 1827 sobre los negocios de su departamento, en GÓMEZ Rodríguez, Luis Horacio (comp.), cit. (n. 32), II, p. 249.

${ }^{34}$ Restrepo, José Manuel, cit. (n. 32), II, p. 249.

35 "Si en la tradición jurídica europea el espacio político se definía a partir de un grado de potestad jurisdiccional (tierra munida de jurisdicción), los territorios eran tales en tanto que jurisdicciones, con independencia del diverso origen y alcance con que el poder así definido estuviera distribuido en el tablero imperial. La soberanía, hasta entonces entendida en términos de superioridad jurisdiccional en lo temporal, no solo perdió su centro de unidad con las crisis de las monarquías ibéricas, sino que su sentido fue transformado a la luz del lenguaje político constitucional vigente. Pero el viejo sentido siguió activo, interactuando a veces con el nuevo, dejando una nueva pluralidad de soberanos relativos, ya sin un claro titular que unificara los espacios. Muchas jurisdicciones se proclamaron soberanas, aunque solo buscaran con esto reafirmar su cuota de poder local". Agüero, Alejandro, Slemian, Andrea y Fernández Sotelo,
} 
modos, la jurisdicción mantuvo la connotación territorial para los encargados de administrar justicia -jueces y tribunales-. El artículo 147 de la Constitución de 1821 determinaba que el Congreso establecería las cortes superiores que juzgara necesarias, "o que las circunstancias permitan crear desde ahora, asignándoles el te r r $i$ torio a que se extienda su respectiva jurisdicción y los lugares de su residencia". En la Constitución de 1832, el término aparecía solamente en el artículo 67, que señalaba que quienes hubieran ejercido "cualquier mando, jurisdicción o autoridad en toda la provincia, al tiempo en que se hace la elección" no podían ser "senadores o representantes, el Presidente y Vicepresidente de la República”. Aquí puede verse el otro sentido de la jurisdicción -como atributo de autoridad-, pero modificado. Si en el periodo colonial la jurisdicción equivalía al m a n d o y a la a u to r i d a d, en el nuevo contexto se entendería como un poder mucho más limitado: la facultad de ciertos funcionarios del Estado para administrar justicia conforme a la ley.

La jurisdicción, en este contexto de construcción de la soberanía estatal, fue adquiriendo en el discurso político y legislativo el significado de función estatal subordinada a las leyes y directrices del poder ejecutivo. Esto no quiere decir que perdiera su connotación amplia como forma de poder público, particularmente entre los jueces inferiores, pero las formas en que en la práctica se manifestaba ese poder en el ámbito de la administración de justicia sufrieron transformaciones. Por ejemplo, a los conflictos entre los jueces ordinarios se sumaron los que podían ocurrir entre aquellos y los jueces militares en un contexto de incremento de los delitos cometidos por soldados en la capital ${ }^{36}$.

El tránsito a una soberanía nacional comenzó a implicar, en el ámbito de la naciente función judicial, una distribución más definida de las c o m p e t e n c i a s -es decir de las funciones- judiciales en las diferentes instancias. Asimismo, aunque los concejos siguieron nombrando a sus alcaldes municipales, en el caso de la capital, la ampliación de la esfera judicial resultado de la reforma de 1825 implicó que la competencia -ya no jurisdicción-de los alcaldes municipales de la capital quedara reducida a los delitos cometidos dentro de ella. Los nuevos alcaldes municipales de los cantones creados para la antigua jurisdicción de Santa Fe se encargarían de conocer de los juicios en primera instancia en sus territorios, ante la imposibilidad material de sostener a los jueces letrados. El término c o m p e t e n c i a mantuvo un sentido territorial, pero como una función ejercida dentro de un territorio delimitado legalmente. Aunque en la práctica no hubiera límites precisos en las divisiones territoriales establecidas en las leyes, la distribución legal de las competencias ya era una diferencia importante con respecto al aparato judicial del virreinato, puesto que implicaba, al menos en teoría, una delimitación más precisa de las actividades de los jueces.

Lo anterior no quiere decir que la antigua forma de entender la jurisdicción desapareciera. Un ejemplo aparece en la ley sobre régimen político de 8 de octubre de 1821, que en principio se trataba, como su desarrollo lo indica, de las autoridades de la rama Ejecutiva. Entre los empleados a que esta ley se refería estaban

Rafael Diego, Introducción general, en Agüero, Alejandro; Slemian, Andrea y Fernández Sotelo, Rafael Diego (coords.) Jurisdicciones, soberanías, administraciones (Córdoba, 2018), p. 21 [19-24].

${ }^{36}$ Por ejemplo, Sección República, Asuntos Criminales, Legajo 30 ff. 681-698. 
los jueces políticos, agentes subalternos de los gobernadores de las provincias y encargados de la administración de los cantones, cuya autoridad aparecía definida como ju ris di c ci ón (además de poder ejercer el conocimiento de causas judiciales de primera instancia en ciertos casos).

Este cambio también expresaba una forma en que la transformación institucional que implicaba la creación del nuevo Estado se manifestaría en el entramado de relaciones en el medio institucional de la administración de justicia. Durante el virreinato habían sido frecuentes los conflictos de jurisdicción, tradicionalmente conocidos como c o m p e te n c i a s, entre la Real Audiencia y los alcaldes ordinarios del cabildo, e incluso entre dichos alcaldes y el virrey. Ahora, el proceso inicial de formación estatal republicano también influiría no solo en la forma de distribuir la función judicial sino además en las formas que tomarían los conflictos de competencia - ya no de jurisdicción- suscitados entre los jueces, lo que se ve desde la propia Constitución de 1821.

Esta Constitución conservaba el sentido tradicional del término c o m p e t e n c i a como conflicto jurisdiccional. Por ejemplo, según su artículo 143, a la Alta Corte de Justicia correspondía el conocimiento de (entre otros asuntos) "las competencias suscitadas o que se suscitaren en los tribunales superiores". Ese era el mismo sentido con que el término aparecía en las discusiones del Congreso de Cúcuta. Al mismo tiempo, la propia Constitución se refería al "tribunal o juez competente", lo que quiere decir que el sentido tradicional coexistía con el nuevo en un mismo documento. La superposición de ambos significados durante el periodo se observa en diferentes documentos de la época; por ejemplo, en 1820 el secretario de Estado hablaba de las "competencias que ya comenzaban a suscitarse sobre la autoridad que debía conocer" en las causas de bienes confiscados ${ }^{37}$. El mismo año, en una causa por hurto, un fiscal se refería a que un gobernador pretendía "la competencia de conocer" en un delito ${ }^{38}$. En 1826, la Alta Corte de Justicia ya se refería a su c o m p e te n c i a ${ }^{39}$. El año siguiente, la Corte Superior Departamental de Cundinamarca, al resolver un recurso de nulidad, argumentaba que la confesión hecha ante juez in c o m pete n te era ipso jure nula, por lo que no podía condenarse al reo "si la i n c o m p e te n c i a del juez [era] por falta de jurisdicción, como lo fundan los prácticos, entre ellos Antonio Gómez en el cap. 12, tit. 3, num. 8 de sus resoluciones, y Hevia Bolaños, 3a parte del juicio criminal, parágrafo 13 , num. $15^{\prime 40}$. Como se ve, en este texto los ministros de la Corte ya hablan de incompetencia, que entraba a reemplazar el sentido de la definición "defecto de jurisdicción” de Juan de Hevia Bolaños ${ }^{41}$.

En la década de 1830 el nuevo sentido de c o m p e te n c i a como distribu-

\footnotetext{
${ }^{37}$ Vergara, Estanislao, Memoria del encargado del despacho del interiory de justicia de Cundinamarca, en Gómez Rodríguez, Luis Horacio (comp.), cit. (n. 32), I, p. 24.

${ }^{38}$ AGN, Sección República, Asuntos Criminales, Legajo 66, ff. 468r-472v.

${ }^{39}$ A GN, Sección República, Juzgados y Tribunales, Legajo 21, f. $111 \mathrm{r}$.

${ }^{40}$ Ibíd., f. 378v.

${ }^{41}$ Hevia Bolaños, Juan de, Curia Filipica, primero y segundo tomo (nueva impresión, Madrid, en la Oficina de Pedro Marín, Impresor de la Secretaría del Despacho Universal de Guerra, $1771[1644])$, p. 234.
} 
ción funcional de la jurisdicción, y del correlativo i n c o m p e t e n c i a, parecían haberse establecido. La Constitución de 1832, por ejemplo, ya solo se refería a autoridades, jueces y tribunales competentes, dejando así de lado una disposición como la del artículo 143 de la Constitución anterior. En 1835 el juez parroquial de la Catedral informaba al Tribunal del distrito de Cundinamarca que se había suscitado una "incompetencia de jurisdicción"

\section{ReCOMPOSICIÓN Y REORGANiZACIÓN DE LA Justicia CRIMINAL EN BOGOTÁ Y LOS CANTONES CORRESPONDIENTES A SU ANTIGUA JURISDICCIÓN (1819-1832)}

Los cambios institucionales en la organización judicial comenzaron a materializarse a partir de 1821. En el periodo 1810-1816 no hubo cambios sustanciales de la estructura de la justicia ordinaria, y el decreto de Tribunales de Primera Instancia y una Alta Corte de Justicia de 6 de octubre de 1817 no alteró el aparato judicial en Santa Fe, que seguía estando en manos de los alcaldes ordinarios y la Real Audiencia hasta 1819, como muestran las causas judiciales del periodo. Por su parte, el gobierno republicano expidió el 25 de febrero de 1819 un reglamento provisorio para el poder judicial en el que se establecía que estaría "depositado en una corte suprema de justicia que resida en la capital, y los demás tribunales establecidos o que se establecieren en territorio de la República" (art. 1). Esta corte entraría en funcionamiento en 1820.

Una de las primeras medidas efectivas del nuevo gobierno fue la supresión de los alcaldes de la Santa Hermandad a través del decreto de 3 de enero de 1822 firmado por Santander. El argumento aducido en el decreto sobre esta medida era que ni la ley de departamentos ni la de tribunales de 14 de octubre de 1821 hablaban de estos alcaldes, cuyas causas de conocimiento habían pasado "los alcaldes ordinarios y a los pedáneos en sus respectivos casos" ", lo que además los hacía i n ú t i l e s según José Manuel Restrepo ${ }^{44}$. Ahora bien, a diferencia del caso argentino, esta medida no coincidió con la supresión de los cabildos ni tampoco fueron reemplazados por los jueces de $\mathrm{paz}^{45}$. Aunque el argumento del decreto Santander era de índole formal -el hecho de que estos alcaldes no fueran mencionados en las leyes de departamentos y de tribunales-, se trataba de una medida que debió ser efectiva porque la institución venía en decadencia en el tramo final del periodo Colonial. En cuanto a la figura de los jueces paz, aunque fueron creados por la Ley orgánica de Tribunales de 10 de mayo de 1834, según la información actualmente disponible parece que en la práctica tuvieron poca importancia y duración, de nuevo a diferencia de Argentina ${ }^{46}$.

${ }^{42}$ AGN, Sección República, Asuntos Criminales, Legajo 92, f. 667r.

${ }^{43}$ Decreto de 3 de enero de 1822.

${ }^{44}$ Restrepo, José Manuel, cit. (n. 32), I, p. 129.

${ }^{45}$ BARriera, Darío, Justicias rurales: el oficio de alcalde de la bermandad entre el derecho, la bistoria y la historiografia (Santa Fe, Gobernación del Rio de la Plata, siglos XVII a XIX), en Andes, 24 (2013), pp. 17-61.

${ }^{46}$ Sobre este caso, BARriera, Darío, ¿Qué nos enseña la historia de las instituciones judiciales?, en BANDIERI, Susana y FERNÁNDEZ, Sandra (coords.), La historia argentina en perspectiva local y regional: 
Los alcaldes ordinarios de Santa Fe siguieron encargándose de la primera instancia hasta $1825^{47}$. La Constitución de 1821, en su artículo 149, los consideraba como provisionales antes de que el Congreso organizara la administración de justicia por una ley, lo que indica el interés temprano de los nuevos gobernantes por centralizar esta actividad ${ }^{48}$. El gobierno, a través de la ley de 14 de octubre de 1821 "sobre la organización de tribunales y juzgados" los mantuvo como jueces de primera instancia en causas criminales de cualquier cuantía (art. 100); es decir que en ese aspecto conservó la situación existente durante el gobierno virreinal. Asimismo, en causas mayores de 25 pesos debían juzgar asesorados de letrado (art. 105). Así pues, entre 1820 y 1825 la justicia criminal en primera instancia en el territorio de la antigua jurisdicción de Santa Fe estuvo en manos de los alcaldes ordinarios de la ciudad ${ }^{49}$.

El desarrollo de la actividad judicial no sufrió variaciones estructurales: la primera parte del proceso penal, es decir, el sumario, era llevado a cabo por los propios alcaldes luego de la remisión de los reos que hacían los alcaldes de barrio. Estos también podían formar el sumario si habían sido comisionados para ello en los casos de delitos cometidos en la ciudad, lo que también hacían los alcaldes pedáneos de los pueblos de la provincia. La etapa probatoria, de alegatos y juzgamiento también mantuvo su estructura propia del modelo castellano vigente desde el periodo Colonial. También vale la pena insistir en que los alcaldes ordinarios, como jueces legos, siguieron decidiendo en los juicios con asesoría de letrados.

A través de la reforma de 1825 (ley de 11 de mayo), el Estado atribuyó el conocimiento de la primera instancia de las causas criminales a los jueces letrados y, de forma subsidiaria, a los jueces municipales. Los primeros debían ser nombrados por el Poder Ejecutivo, mientras que los nombramientos de los jueces municipales estarían en las municipalidades, aunque de todos modos para el gobierno eran "empleados del orden judicial" del Estado en ciernes, lo que refleja las intenciones centralizadoras de la reforma ${ }^{50}$. Los jueces letrados representaban asimismo el interés gubernamental por una mayor formalización de la justicia, es decir, por que estuviera más apegada a las leyes republicanas, puesto que, a diferencia de los alcaldes municipales, debían ser abogados "recibidos o incorporados

nuevas miradas para viejos problemas (Buenos Aires, 2017), II, pp. 133-156. Aunque esta figura es de interés incluso para el caso colombiano, queda por fuera de este estudio, que está enfocado en la justicia ordinaria.

${ }^{47}$ En 1821 algunos hurtos cometidos por indígenas llegaron a conocimiento del gobernador político en virtud de un decreto del gobierno, pero esa medida no continuó.

${ }^{48}$ Art. 149: "Los juzgados inferiores subsistirán por ahora en los términos que se prescribirán por ley particular, hasta tanto que en el Congreso varíe la administración de justicia”.

${ }^{49}$ Como se, por ejemplo en: AGN, Sección República, Asuntos criminales, Legajos 16 ff. 262328; 64 ff. 1-35; 25 ff. 868-884; 46 ff. 912-921; 68 ff. 385-397; 16 ff. 262-327; 18 ff. 854-872; 18 ff. 875-950; 36 ff. 825-873; 7 ff. 514-537; 30 ff. 681-698; 52 ff. 200-406; 22 ff. 705-760; 21 ff. $77-87 ; 30$ ff. 175-211; 65 ff. 527-570; 32 ff. 590-756; 42 ff. 343-381; 14 ff. 653-787; 86 ff. 241-243; 3 ff. 170-182; 6 ff. 624-669; 32 ff. 544-589; 19 ff. 700-783; 16 ff. 329-400; 21 ff. 77-87; 30 ff. 175-211; 60 ff. 840-889; 22 ff. 386-512; 50 ff. 434-466.

${ }^{50}$ Sото, Francisco, Exposición que el secretario del interior y relaciones exteriores del gobierno de la Nueva Granada, hace al congreso constitucional del año de 1833, sobre los negocios de su departamento, en Gómez Rodríguez, Luis Horacio (comp.), cit. (n. 32), III, p. 122. 
en alguno de los tribunales de la República" (art. 96). Sin embargo, las exigencias no se limitaban a ser ciudadano y abogado recibido en un tribunal, sino que además estaban la de "tener reputación y concepto de notoria probidad y patriotismo" (art. 96). Esta disposición muestra la importancia que seguían teniendo para los nuevos gobernantes las cualidades personales del juez, una característica esencial de la justicia de Antiguo Régimen, en este caso dentro de las exigencias de un gobierno que buscaba imponer su soberanía sobre el territorio de la temprana nación por medios como la justicia ordinaria.

Las dificultades para el establecimiento de los jueces letrados eran reconocidas por el propio gobierno. En el texto de la ley se señalaba que el Poder Ejecutivo no establecería jueces letrados sino en los cantones donde fuera más necesario y donde hubiera suficientes letrados (abogados), además de dar la posibilidad de que tuvieran una jurisdicción de más de un cantón ${ }^{51}$. El año siguiente, el secretario de Estado Restrepo seguía señalando que solo sería posible establecerlos en los lugares en los que se dieran las condiciones antes indicadas, "según los informes pedidos a las autoridades de las provincias". Mientras tanto, continuaba, los jueces municipales seguirían "conociendo de las causas y procesos atribuidos a los de letras" ${ }^{52}$. Al ser jueces legos, esto lo harían con asesoría de letrado.

Otro motivo para la continuidad de los jueces municipales en el conocimiento de los procesos en primera instancia fue la oposición de los pueblos a los jueces letrados, que de hecho implicó su suspensión. Simón Bolívar había observado que algunos pueblos se hallaban descontentos con la institución de los jueces letrados, que los propios de los cabildos no alcanzaban para darles el sueldo asignado, y que los alcaldes municipales podían continuar ejerciendo las funciones de jueces de primera instancia, por lo que "tuvo por conveniente suspender el establecimiento de los jueces letrados, usando de sus facultades extraordinarias" ${ }^{53}$. El decreto en cuestión era el de noviembre 24 de 1826, que no solo suspendía los nombramientos, sino que además ordenaba que los nombrados cesaran sus funciones, además de determinar que los alcaldes municipales continuarían administrando justicia en primera instancia "conforme a la ley". Así, los jueces letrados solo funcionaron en Bogotá en 1825, y solo en 1832 comienza a haber nuevos nombramientos como jueces de letras en la capita ${ }^{54}$.

$\mathrm{El}$ decreto anterior permite observar las limitaciones materiales (recursos y humanas) y socioculturales (la importancia que los pueblos seguían atribuyendo al nombramiento de sus propias justicias) que eran un obstáculo para los esfuerzos centralizadores de la justicia por parte del gobierno. Además estaba la preocupación por la formalización y organización institucional; Francisco Soto, por ejemplo, argumentaba que los alcaldes municipales carecían de conocimientos jurídicos, motivo por el cual no podían dar buena dirección a los negocios, y que

\footnotetext{
${ }^{51}$ Parágrafos 1 y 2 , artículo 95.

${ }^{52}$ Restrepo, José Manuel, cit., (n. 32), III, p. 21.

${ }^{53}$ Restrepo, José Manuel, cit. (n. 32), II, pp. 249 y 250.

${ }^{54}$ Por ejemplo, AGN, Sección República, Asuntos criminales, Legajo 37, ff. 542-633.
} 
teniendo que enviar los expedientes en asesoría muchas veces a una gran distancia, se entorpecían estos y dilataban "con perjuicio de los intereses públicos"

Un caso de hurto de noviembre 1825, que alcanzó una particular resonancia, permite también ilustrar este problema. De acuerdo con el artículo 101 de la ley de 11 de mayo 1825, los jueces letrados debían dar cuenta a la corte superior respectiva, dentro del tercer día, de las causas criminales que hubieran iniciado. Para la Alta Corte de Justicia, esta obligación también la tenían los alcaldes municipales que continuaron administrando justicia ante la imposibilidad de establecer jueces letrados. El alcalde municipal de La Mesa, en un informe a la Alta Corte de Justicia, argumentaba que la obligación del mencionado artículo era solo para los jueces letrados. A su juicio, era cierto que "por un defecto" los alcaldes municipales de ese cantón ejercían la jurisdicción de los jueces letrados; pero, continuaba, "no sería justo exigir de un juez lego aquella nimia escrupulosidad y atención en todos los ápices del derecho, que el legislador no demanda sino de unos jueces a quienes ya supone versados en la ciencia de la Jurisprudencia", por lo que pidió al gobierno el establecimiento de jueces letrados en este cantón, pues, continuaban "no es dable que sin ser yo legista se haya de cargarme la responsabilidad de un juez letrado" 56 . Este caso muestra, pues, las dificultades que podían tener los jueces legos ante una administración de justicia que en las disposiciones normativas se concebía en términos cada vez más formalistas y apegados a la ley.

\section{Los ALCALDES MUNiCIPALES (1825-1832)}

Durante los años de 1825 y 1826, la mayoría de causas criminales fueron conocidas por los alcaldes municipales, mientras que algunas lo fueron por el único juez letrado que se nombró en Bogotá ${ }^{57}$. Es decir que, aunque llegó a establecerse ese último cargo, no solo tuvo escasa duración inicialmente, sino que además no reemplazó a los jueces municipales en la primera instancia en el tiempo en que funcionaron. La diferencia más notoria es que los pocos casos asumidos por el juez letrado fueron sentenciados directamente por este, mientras que en los casos en que la causa estaba a cargo de los alcaldes municipales, lo seguían haciendo asesorados por un letrado, de acuerdo con el cap. 3, ley de ll de mayo de 1825.

Otra implicación de la ley orgánica del Poder Judicial de 11 de mayo 1825 fue una primera desconcentración de la justicia de primera instancia en los alcaldes municipales de los cantones. El caso de la provincia de Bogotá, entre 1819 y esa ley los alcaldes ordinarios se encargaban de los juicios de primera instancia para la ciudad y los cantones correspondientes a los antiguos corregimientos, mientras que a partir de 1825 correspondió a los alcaldes municipales de los cantones. En este momento no es posible identificar el origen de esos nuevos jueces, pero es probable que en algunos casos hubieran sido previamente alcaldes pedáneos de

\footnotetext{
${ }^{55}$ Soto, Francisco, cit. (n. 32), III, p. 125.

${ }^{56}$ AGN, Sección República, Juzgados y Tribunales, Tomo 20, f. 870r. y v.

${ }^{57}$ AGN, Sección República, Asuntos Criminales, Legajos 10 ff. 461-524; 7 ff. 963-990; 10 ff. 814-837; 60 ff. 973-1014; 57 ff. 515-537.
} 
los pueblos, puesto que su nombramiento no dependía del gobierno, sino que era una prerrogativa de los pueblos.

Los alcaldes municipales de los cantones debían encargarse del conocimiento de la primera instancia de las causas criminales a partir de la reforma de 1825 , lo que efectivamente comenzaron a hacer, como muestran los juicios criminales del periodo ${ }^{58}$. De todos modos, debe aclararse que en la documentación existente en el AGN solo se encuentran alcaldes municipales conociendo causas criminales en los cantones de Zipaquirá, Chocontá, La Mesa, Guaduas y Funza, lo que indica que su establecimiento se desarrolló de manera irregular.

Las comisiones para el desarrollo del sumario continuaron. Los comisionados eran, al igual que en el periodo anterior, los jueces inferiores, que en el caso de los alcaldes de los barrios de la capital pasaron a llamarse parroquiales, al igual que los pedáneos de las antiguas parroquias. Una diferencia era que, mientras en el periodo anterior las comisiones fueron una figura muy usada por la Real Audiencia, ahora eran ordenadas por los alcaldes ordinarios, hasta 1825, y en los años posteriores por los alcaldes municipales.

La justicia militar no parece haberse constituido en una instancia extraordinaria de juzgamiento para la gente del común -aunque en ocasiones los soldados ayudaban a capturar a uno que otro ladrón-, y, siguiendo las disposiciones españolas vigentes, los delitos que conocía eran aquellos cometidos por los miembros de sus filas. Esta situación vuelve a demostrar que la prohibición constitucional a los tribunales extraordinarios tenía un sentido de establecer una limitación hacia el futuro como declaración de principios del nuevo gobierno, y no el de sancionar una situación vigente.

Los alcaldes municipales tenían también la j u r i s d i c c i ón, según el artículo 154 de la ley de 11 de 1825, para "castigar correccionalmente" con arrestos de hasta tres días o multas de hasta 25 pesos, las "faltas o excesos" que no fueran "de gravedad, contra el buen orden, honestidad, decencia pública y seguridad de los habitantes". Esta disposición, de nuevo, recoge legalmente una facultad propia de la potestad económica de los alcaldes ordinarios, como era la de "castigar correccionalmente", lo que muestra de nuevo la continuidad de criterios tradicionales en el lenguaje legal referido a la actividad de los jueces. Los castigos extrajudiciales, aplicados por los alcaldes ordinarios como c o r r e c c i ó n e c o nó m i c a, eran normales en la capital durante el virreinato, con lo que la nueva ley en este caso sí recogía una práctica vigente.

${ }^{58}$ Por ejemplo: AGN, Sección República, Asuntos Criminales, Legajos 7 ff. 963-990; 20 ff. 60-64; 3 ff. 457-545; 6 ff. 741-875; 60 ff. 973-1014; 34 ff. 174-269; 19, ff. 1072-1102; 24 ff. 568r-589v.; 10 ff. 345-375; 6 ff. 349-369; 25 ff. 891-894; 55 ff. 649-763; 41 ff. 772-782; 68 ff. 115-120; 5 ff. 841-854; 14 ff. 571-573; 19 ff. 999-1004; 36 ff. 969-974; 43 ff. 1037-1047; 5 ff. 550-566; 10 ff. 734-738; 25 ff. 480-484; 42 ff. 1070-1074; 57 ff. 737-739; 61 ff. 123-125; 61 ff. 123-125; 66 ff. 671-673; 32 ff. 823-1029; 67 ff. 720-749; 69 ff. 17-21; 69 ff. 961-965; 71 ff. 263-291; 75 ff. 1014-1018; 75 ff. 1024-1029; 79 ff. 362-372; 79 ff. 915-918; 81 ff. 827-832; 85 ff. 209-213; 92 ff. 677-680; 92 ff. 668-671. 


\section{Primera, SEgunda y TERCERA INSTANCIA EN EL NUEVO Poder Judicial Republicano}

La primera instancia sufrió las modificaciones ya mencionadas. La segunda instancia se separó institucionalmente de la primera al desaparecer la figura de los alcaldes de Corte junto con la Real Audiencia, y pasó a la corte del Distrito del Centro (dentro de cuya jurisdicción estaba la provincia de Bogotá) ${ }^{59}$, encargada de conocer las apelaciones y consultas de las sentencias de los jueces de primera instancia. La tercera instancia (nulidades y súplicas a las sentencias de la corte del Distrito) estaría en cabeza de la Alta Corte de Justicia, que además seguía actuando como órgano consultor del Ejecutivo siguiendo la costumbre del periodo Colonial, cuando la Audiencia cumplía esa función con respecto al virrey.

Las limitaciones materiales del nuevo Estado, además de impedir el establecimiento de los jueces letrados, se manifestaban también en la segunda instancia a pesar de la creciente cantidad de causas criminales por resolver. La ley de 11 de mayo de 1825, por ejemplo, determinaba la reducción de los ministros de las cortes departamentales. En el caso de la del Centro, la Alta Corte de Justicia se reunió en Acuerdo en septiembre 15 de 1825 (nótese que esto remite al a c u e r d o de la Real Audiencia) para hacer dicha reducción, y encontraron que no había necesidad de hacerla. El motivo era que en dicha corte se encontraban ya seis ministros en propiedad, por lo que bastaba que el Poder Ejecutivo declarara por tales ministros a Diego Fernando Gómez, Antonio Viana, Joaquín Ortiz, Alejandro Osorio e Ignacio Herrera. Los dos últimos quedarían en calidad de fiscales, mientras que Ortiz y Herrera estaban procesados, lo que, a juicio de la Alta Corte, no afectaba que pudieran ser propuestos según el artículo 15 de la ley de 11 de mayo $^{60}$.

Asimismo, se observa que en ocasiones los ministros nombrados no aceptaban o aceptaban con reservas los nombramientos en la Corte por ser una actividad menos lucrativa que el ejercicio privado de su profesión. En 1825, por ejemplo, un abogado aceptaba la plaza de juez interino en la Alta Corte de justicia a pesar de que ese destino era perjudicial para sus intereses, "por considerarme obligado a emplearme con preferencia en el servicio de la nación siempre que el gobierno me lo exija" ${ }^{\prime 1}$. Esto, de nuevo, es un ejemplo de las limitaciones dentro de las que funcionaba la administración de justicia en ese periodo.

\footnotetext{
${ }^{59} \mathrm{El}$ artículo 9 de la ley juzgados y tribunales de 14 de octubre de 1821 estableció que habría tres cortes superiores de justicia: la del distrito del norte, con sede en Caracas, la del distrito del sur, con sede en Quito, y la del distrito del centro, con sede en Santa Fe.

${ }^{60}$ A GN, Sección República, Juzgados y Tribunales, tomo 20, f. 486r.

${ }^{61}$ Ibíd., f. 209 r.
} 


\begin{tabular}{|c|c|c|}
\hline Primera instancia & SEGUNDA INSTANCIA & TERCERA INSTANCIA \\
\hline $\begin{array}{l}\text { Sumario } \\
\text { alcaldes pedáneos y de } \\
\text { barrio (1819-1825) } \\
\text { alcaldes parroquiales } \\
\text { (1825 en adelante) } \\
\text { Sumario y causa } \\
\text { alcaldes ordinarios de } \\
\text { Santa Fe (1819-1825) } \\
\text { alcaldes municipales (1825 } \\
\text { en adelante) } \\
\text { jueces letrados (1825) }\end{array}$ & $\begin{array}{l}\text { Corte de Justicia del } \\
\text { Centro } \\
\text { Pasó a llamarse Tribunal } \\
\text { Superior de Cundinamarca } \\
\text { en } 1834 \text {. } \\
\text { Conocía las apelaciones y } \\
\text { consultas de las sentencias } \\
\text { de primera instancia. }\end{array}$ & $\begin{array}{l}\text { Alta Corte de justicia } \\
\text { Entre otras funciones, } \\
\text { conocía de los recursos } \\
\text { de nulidad contra las } \\
\text { sentencias de las cortes } \\
\text { superiores, dirimía las } \\
\text { competencias entre ellas, } \\
\text { entre otras funciones (art. } \\
4 \text { ley de } 11 \text { de mayo de } \\
\text { 1825). } \\
\text { En la práctica también } \\
\text { conocía de las súplicas } \\
\text { a las sentencias de las } \\
\text { Cortes superiores }\end{array}$ \\
\hline $\begin{array}{l}\text { Competencias especiales } \\
\text { en primera instancia } \\
\text { Gobernadores políticos } \\
\text { (en caso de indígenas) } \\
\text { (solo en 1821) } \\
\text { jueces políticos }\end{array}$ & & \\
\hline
\end{tabular}

TABla n..$^{\circ}$ 1. Agentes de la Justicia CRIMINAL EN PRIMERA, SEgUnda Y TERCERA INSTANCIA PARA LA CAPITAL ${ }^{62}$

\section{CONFLictos DE COMPETENCIA DENTRO DE UNA INCIPIENTE} DIVISIÓN DE PODERES

Los conflictos entre autoridades judiciales, frecuentes durante el periodo colonial, continuaron en las décadas de 1820 y 1830, en un contexto de incipiente división de poderes. Los constituyentes hispánicos "tuvieron que enfrentarse a los mismos problemas que previamente habían ocupado a norteamericanos y franceses" resultado de la división constitucional de los poderes, pues era diferente establecer los términos normativos sobre este asunto que "rellenar con precisión las nuevas divisiones de poder que cancelaban la historia previa" ${ }^{63}$. En otras palabras, la división de poderes era un principio normativo que no podía materializarse de forma inmediata en los agentes judiciales, empezando por que ni siquiera en la conciencia de los legisladores había cobrado una forma definida. El gobierno, por ejemplo, atribuyó funciones judiciales (bajo la denominación negocios contenciosos) a los intendentes en la ley de 8 de octubre

${ }^{62}$ Elaborada por el autor de este artículo a partir de la información legal y de archivo consultada.

${ }^{63}$ Lorente, Marta, Constitucionalismo hispánico (una propuesta de lectura), en CaLderón, María Teresa (coord.), Politica y constitución en tiempos de las independencias (Bogótá, 2017), pp. 87-129. 
de 1821 sobre régimen político (art. 9), lo que dio origen a una "profusión de consultas de los intendentes y asesores letrados" al gobierno ${ }^{64}$.

El problema se observa asimismo con la figura de los jueces políticos que, a pesar de formar parte de la rama Ejecutiva, tenían j u ri s di c c ión, como he mencionado. La misma ley sobre régimen político de 1821 establecía en el artículo 37 la posibilidad de que ejercieran su jurisdicción conociendo causas criminales en primera instancia donde no hubiera alcaldes ordinarios que, como se ha visto, fueron reemplazados por los municipales en 1825 .

La situación era, pues, la siguiente: en primer lugar, una coexistencia de significados de las nociones de jurisdicción y competencia, y luego unas leyes que no podían d e s a r r o 11 a r el principio de división de poderes porque en la conciencia de sus autores no existía una claridad de esa división y distribución de funciones. Esto no solo se veía en las contradicciones entre diferentes disposiciones, sino además en la propia materialización de los cambios en la disposición de los agentes de la justicia a partir de esas transformaciones en el discurso normativo.

Un ejemplo es un caso ocurrido en 1830. Ese año la corte de apelaciones del Centro consultó al gobierno sobre la subsistencia de jurisdicción en los jueces políticos para conocer causas de hurto de menor cuantía a raíz de una causa en Chocontá. El fiscal de la Corte argumentaba que el artículo 28 del decreto de 22 de diciembre de 1827 sujetaba el conocimiento de dichas causas a los jueces políticos y los autorizaba para imponer castigos correccionales, procediendo sumaria y económicamente en los cantones donde no hubiera jefe de policía, "o donde a los jueces políticos no estuvieran conferidas las atribuciones de aquellos”. Así, donde no hubiera jueces políticos o jefes de policía no había quien conociera de esas causas, por lo en esos casos los reos quedaban sujetos al procedimiento de la ley de 3 de mayo de 1826 y a las penas detalladas en ella (lo que implica que la competencia estaría en los alcaldes parroquiales y municipales), de lo que resultaba "un diverso modo de proceder en unas mismas causas en unos cantones, que en otros, y una desigualdad de pena a unos mismos delitos".

Asimismo, según el fiscal, por el decreto de 3 de agosto de 1820 los jueces políticos, que pasaron a denominarse jefes políticos municipales, no podían ejercer funciones judiciales, de manera que las atribuciones de los jefes de policía no podían ya conferirse a ellos. De ahí que la ley no atribuyera a ninguna autoridad el conocimiento sumario de las causas de hurto de menor cuantía en los cantones donde no hubiera jefes de policía, y en ese caso parecía que su conocimiento correspondía a los alcaldes municipales, de acuerdo con el artículo 106 de la ley de 11 de año de 1825, puesto que debían ejercer las funciones de los jueces letrados cuando no los hubiera, y a estos correspondía, según la atribución cuarta

${ }^{64}$ Martínez Garnica, Armando, cit. (n. 3), p. 114. Según Martínez, el examen que de ese asunto hizo el Consejo de Gobierno en 1821 "concluyó que la práctica judicial de los intendentes obstaculizaba la separación de los poderes públicos, por lo cual recomendó una modificación de la ley orgánica de los departamentos para transferir a los tenientes asesores letrados las causas judiciales, reservando a los intendentes y gobernadores solamente las funciones militares y el fomento de las provincias". 
del artículo 98, conocer de todos los negocios criminales cuyo conocimiento no estuviera especialmente atribuido a dicha autoridad por la ley.

Ahora bien, para el fiscal, donde había jefes de policía, estos tenían la atribución de conocer de las causas de hurto de menor cuantía, pero donde no los hubiera, la ley no atribuía a otra autoridad el conocimiento de esas causas. De ese modo se uniformaba el procedimiento de las causas, y las penas serían iguales en todos los cantones para unos mismos delitos. La Corte falló siguiendo la argumentación del fiscal, pero su fallo es ilustrativo también de una controversia que era propia de este periodo de poca claridad entre las funciones diferentes autoridades, en este caso encargadas de perseguir y castigar los delitos ${ }^{65}$.

Otro ejemplo de esta ambigüedad se derivaba de la atribución a los gobernadores políticos del conocimiento de las causas criminales en las que los reos eran indígenas, determinada por Santander en la Superior Declaratoria de 27 de octubre de 1820, que implicaba una "subrogación de la autoridad que gozaban los virreyes en el conocimiento de los asuntos en que los indios litigaban como reos" ${ }^{\prime 66}$. Era, pues, una disposición que conservaba una disposición del periodo colonial en un contexto nuevo ${ }^{67}$, pero que al mismo tiempo no tenía en cuenta las cargas de los nuevos empleados ejecutivos. Por esta razón, durante el tiempo en que estuvo en vigor (hasta 1821) esta declaratoria contribuyó a alargar y complicar las causas contra indígenas ${ }^{68}$. Las causas pasaban a los gobernadores a través de los alcaldes ordinarios a cuyo conocimiento habían llegado inicialmente, y las respuestas de los primeros eran en dos sentidos: o devolver las causas a los segundos, o despacharlas lo más pronto posible dejando libres o condenando muy levemente a los reos. A pesar de esto, el tiempo que transcurría mientras la causa iba de un funcionario a otro hacía que las causas terminaran demorándose más de lo que los gobernadores habrían considerado adecuado.

También ocurrieron conflictos de competencia entre la jurisdicción militar y la ordinaria. Luego de las guerras de Independencia, muchos de quienes habían participado como combatientes y mantenían su condición militar habían terminado cometiendo delitos que terminaban en conocimiento de su propia jurisdicción. Un caso ocurrido en 1821 a raíz de un hurto cometido por un soldado dio origen a un conflicto de esta naturaleza. Inicialmente, el alcalde comisario del barrio de Las Nieves dio noticia sobre el asunto a Mariano Tovar, alcalde ordinario de primer voto, quien a su vez ordenó recibir la sumaria información. El juzgado militar reclamó para sí la competencia, lo que motivó la consulta a la Corte Superior de Justicia del Centro. En el proceso de resolución del recurso, el fiscal señaló que el caso estaba comprendido dentro de la Real cédula de 29 de marzo de 1798, que era la misma orden de 8 de mayo de 1797 y la ley 5 tit. 9 lib. 12 de la Novísima Recopilación, referida a los delitos cometidos por soldados

\footnotetext{
${ }^{65}$ Archivo de la Corte Suprema de Justicia, tomo 20.

${ }^{66}$ AGN, Sección colonia, Indios, Legajo 1, ff. 62r. y 865r., 923r., entre otros.

${ }^{67} \mathrm{Y}$, de hecho, en la práctica el virrey no conocía los juicios por delitos cometidos por indígenas por fuera de sus resguardos, sino los jueces ordinarios.

${ }^{68}$ AGN, Sección República, Asuntos Criminales, Legajos 46 ff. 912-921; 68 ff. 385-397; 14 ff. 574-602; 37 ff. 936-964; 10 ff. 93-168; 25 ff. 868-884.
} 
desertores. Por este motivo, argumentaba que el sumario debía remitirse al juez militar para que allí continuara la causa "con arreglo a leyes militares". La Corte aceptó el dictamen del fiscal ${ }^{69}$.

\section{Conclusiones}

El tránsito de la administración de justicia colonial al poder judicial republicano temprano fue un proceso complejo. Los cambios normativos que iniciaban en las constituciones no podían modificar una realidad judicial que venía funcionando a partir de presupuestos muy distintos. Y, de hecho, las propias leyes muestran las dificultades para diferenciar las funciones administrativas y judiciales a la hora de distribuirlas entre los empleados públicos.

También existieron limitaciones materiales para una formación temprana de los niveles inferiores de la justicia, que comenzaban por las dificultades del Estado en ciernes para establecer una burocracia judicial pagada con sus recursos. Esto se ve con el fracaso inicial de los jueces letrados y la continuidad de los alcaldes municipales, jueces legos, como juzgadores de primera instancia a partir de 1825 .

Los jueces municipales, de todos modos, permitieron una desconcentración de la justicia de primera instancia a pesar de esas limitaciones, lo que puede interpretarse como un fortalecimiento del poder de los pueblos frente al gobierno, al menos en el ámbito de la jurisdicción. Esta desconcentración implicó además una presencia más efectiva de la justicia ordinaria en el territorio de la provincia de Bogotá, lo que de todos modos era coherente con el interés gubernamental por el control de la delincuencia. Lo anterior a su vez se manifestaría en una mayor cantidad de causas criminales para estos año, como puede observarse en el Archivo General de la Nación.

En este contexto de significados cambiantes de la jurisdicción y de incipiente división de poderes tuvieron lugar conflictos entre autoridades que no deben sorprender, pues la organización judicial del periodo Colonial se basaba en presupuestos distintos como el predominio de la jurisdicción como forma de poder. De todos modos, en el fondo los motivos podían ser análogos a los conflictos jurisdiccionales coloniales, como por ejemplo la lucha por la preeminencia de una autoridad sobre otra. Los casos que mencioné son solo algunos ejemplos de los conflictos de competencia que podían ocurrir en los inicios de la materialización institucional del principio de división de poderes en Colombia, un tema que amerita nuevas investigaciones.

${ }^{69}$ Ibíd., Legajo 30 ff. 681-698. 


\section{BIBLIOGRAFÍA}

Fuentes primarias

Archivos

Archivo General de la Nación. Bogotá, Colombia, Sección República. Fondos Asuntos criminales, Indios, Juzgados y Tribunales.

Archivo de la Corte Suprema de Justicia. Bogotá, Colombia. Tomo 20.

Fuentes primarias impresas

Gómez Rodríguez, Luis Horacio (comp.), Administraciones de Santander (Bogotá, 1990), I-III.

Hevia Bolaños, Juan de, Curia Filipica, primero y segundo tomo (nueva impresión, Madrid, 1771 [1644]).

Plan de reforma o revisión de la Constitución de la provincia de Cundinamarca del año 1812. Sancionado por el Serenísimo Colegio Revisor y Electoral de la misma en sesiones tenidas desde el mes de junio hasta el trece de junio de 1815 (Santa Fe, 1815).

Fuentes secundarias

Agüero, Alejandro; Slemian, Andrea y Fernández Sotelo, Rafael Diego, Introducción general, en Agüero, Alejandro; Slemian, Andrea y Fernández Sotelo, Rafael Diego (coords.) Jurisdicciones, soberanias, administraciones (Córdoba, 2018), pp. 19-24.

Balaguer Callejón, María Luisa, La división de poderes en la Constitución de Cádiz de 1812, en Revista de Derecho Político, 83 (2012), pp. 18-41.

Barbosa Delgado, Francisco, Justicia: rupturas y continuidades. El aparato judicial en el proceso de configuración del Estado-nación en Colombia (Bogotá, 2007).

Barreneche, Owaldo, Crime and the Administration of Justice in Buenos Aires, 1785-1853 (Lincoln, 2006).

BARrIERA, Darío, Justicias, jueces y culturas jurídicas en el siglo XIX rioplatense, en Nuevo Mundo Mundos Nuevos (2010) [Disponible en http://journals.openedition.org/ nuevomundo/59252].

- Justicias rurales: el oficio de alcalde de la hermandad entre el derecho, la historia y la historiografía (Santa Fe, Gobernación del Río de la Plata, siglos XVII a XIX), en Andes, 24 (2013), pp. 17-61.

- ¿Qué nos enseña la historia de las instituciones judiciales?, en Susana BANDIERI, Susana y FERNÁNDEZ, Sandra (coords.), La historia argentina en perspectiva local y regional: nuevas miradas para viejos problemas (Buenos Aires, 2017), II, pp. 133-156.

Bushnell, David, El régimen de Santander en la Gran Colombia (Bogotá, 1966 [1954]).

Clavero, Bartolomé, El orden de los poderes. Historias constituyentes de la trinidad constitucional (Madrid, Trotta, 2007).

Colmenares, Germán, El manejo ideológico de la ley penal en un periodo de transición, en Historia Crítica, 4 (1990), pp. 5-45.

Díaz Bravo, Enrique, La separación de poderes en la primera constitución española, en Nómadas. Revista Crítica de Ciencias Sociales y Jurídicas, 33 (2012), pp. 275-293.

Galante, Miriam, La historiografía reciente de la justicia en México, siglo XIX: perspectivas, temas y aportes, en Revista Complutense de Historia de América, 37 (2011), pp. 93-115.

Herrera Ángel, Marta, Las divisiones político-administrativas del Virreinato de la Nueva Granada a finales del periodo colonial, en Historia Crítica, 22 (2001), pp. 76-98.

López GonzÁlez, Georgina, Jueces y magistrados del siglo XIX: continuidad jurídico- 
institucional en México, en Nuevo Mundo Mundos Nuevos (2012) [disponible enhttp:/ / journals.openedition.org/nuevomundo/62666].

Lorente, Marta, Constitucionalismo bispánico (una propuesta de lectura), en Calderón, María Teresa (coord.), Política y constitución en tiempos de las independencias (Bogótá, 2017), pp. 87-129.

Martínez Garnica, Armando. La Agenda de Colombia (Bucaramanga, 2008).

Müssig, UlRIKE, El juez legal (Madrid, 2014).

Ots Capdequí, José María Nuevos aspectos del siglo XVIII español en América (Bogotá, 1946).

Pinto Bernal, José Joaquín y Torres Moreno, James Vladimir. Guerra y Fisco en la Nueva Granada, 1811-1824, en Revista de Economia Institucional, 18/35 (2016), pp. 171-195.

Sosa AbelLa, Guillermo, Representación e Independencia 1810-1816 (Bogotá, 2006).

Toro SILVA, Carlos Alberto, Justicia penal contra los burtos, justicia ordinaria y delincuencia patrimonial. Santa Fe-Bogotá, 1739-1836 (Tesis doctoral, Universidad de los Andes, Colombia, 2019).

Velandia, Roberto, Enciclopedia histórica de Cundinamarca (Bogotá, 1979), I.

VéLez Rendón, Juan Carlos, El establecimiento local de la administración de justicia en Antioquia, 1821-1853. El difícil cumplimiento de una promesa republicana, en Anuario Colombiano de Historia Socialy de la Cultura, 40/1 (2013), pp. 113-143. 